Nuclear Instruments and Methods in Physics Research Section B: Beam Interactions with Materials and Atoms, 2010, 269(2), 100-104, doi:10.1016/j.nimb.2010.10.025

\title{
Effect of swift heavy ion irradiations in polycrystalline aluminum nitride
}

\author{
J.C. Nappé ${ }^{a, *}$, M. Benabdesselam ${ }^{\mathrm{b}}$, Ph. Grosseau ${ }^{\mathrm{a}}$, B. Guilhot ${ }^{\mathrm{c}}$ \\ a École Nationale Supérieure des Mines, SPIN/PMMC, LPMG UMR CNRS 5148, 158 cours Fauriel, 42023 Saint- \\ Étienne cedex 2, France \\ ${ }^{\mathrm{b}}$ Université de Nice - Sophia Antipolis, LPMC UMR CNRS 6622, Parc Valrose, 06108 Nice cedex 2, France

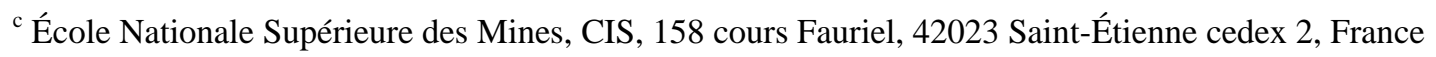

\begin{abstract}
Thanks to its high thermal conductivity, aluminum nitride may be a serious candidate as fuel coating for the Gas Fast Reactor. However, its behavior under irradiation is not entirely well understood. In order to catch a glimpse of this behavior, specimens were irradiated with swift heavy ions of different energies then characterised by both thermally stimulated luminescence and optical absorption spectrophotometry. With these techniques, the native defects, as well as those affected by irradiation, were identified: thus, by comparison to the virgin sample, no new defect detectable by these techniques is created by irradiations. Eventually, the fact that these techniques complement each other allowed to understand the effect of irradiation parameters on the defect concentration.
\end{abstract}

Keywords: AlN, irradiation, swift heavy ions, electronic interactions, thermoluminescence, optical absorption spectrophotometry

PACS: 77.84.Bw, 61.82.Ms, 61.80.Lj, 25.75.Ag, 34.50.Bw, 28.41.Bm, 78.60.Kn, 78.20.Ci

\section{Introduction}

Gas Fast Reactor (GFR) is one of the six new systems considered by Generation IV International Forum (GIF): it is designed to work under helium-pressure and high-temperature (1100-1300 K). These working conditions led to the selection of non-oxide refractory ceramics as fuel coating; the remarkable thermo-mechanical properties of carbides and nitrides make them great candidates for this application. However, their behavior under irradiation has to be studied in more details.

Among the studied materials, aluminum nitride is distinguished by its high thermal conductivity which should ensure the heat transfer between the coolant and the fuel. Actually, the values obtained for commercial aluminum nitride generally range between 160 and $200 \mathrm{~W} \mathrm{~m}^{-1} \mathrm{~K}^{-1}$ [1-4] with the highest value of $320 \mathrm{~W} \mathrm{~m}^{-1} \mathrm{~K}^{-1}$ measured on a single crystal [5].

* Corresponding author. Tel.: +33 477420 213; fax: +33 477499694 .

E-mail: jc.nappe@yahoo.fr. 
Nuclear Instruments and Methods in Physics Research Section B: Beam Interactions with Materials and Atoms, 2010, 269(2), 100-104, doi:10.1016/j.nimb.2010.10.025

The main drawback for the use of aluminum nitride in nuclear facilities is its ability to generate a radioactive long-lived isotope ${ }^{14} \mathrm{C}$ by transmutation of ${ }^{14} \mathrm{~N}[6]$. Nevertheless, this drawback can be reduced by the use of isotope tailored material, in which ${ }^{15} \mathrm{~N}$ replaces ${ }^{14} \mathrm{~N}[7]$.

The behavior of aluminum nitride ceramics is also studied in the framework of fusion reactors, in which this material, thanks to its high electrical resistivity ( $>10^{12} \Omega \mathrm{m}$ at $300 \mathrm{~K}$ [8]), could be used as electric insulator for toroidal current break, neutral beam injectors, and superconducting magnets. Thus, many works have been carried out to understand the behavior of aluminum nitride under neutron irradiation, especially by Yano et al. [7,9-17]. However, as far as we know, no study has been performed concerning the characterization of defects induced by irradiation.

Thus, the aim of this study is to characterize the evolution of native defects of aluminum nitride as a result of swift heavy ion irradiations, using thermally stimulated luminescence and optical absorption spectrophotometry.

\section{Material and methods}

\subsection{Sample preparation and irradiation}

The studied material was obtained by sintering of AlN powders with $\mathrm{Y}_{2} \mathrm{O}_{3}$ (sintering aid: 3 mol\%) at $2123 \mathrm{~K}$ in nitrogen atmosphere during $3 \mathrm{~h}$. This polycrystalline aluminum nitride consists of $8 \mu \mathrm{m}$ grains with $0.89 \%$ of oxygen. Its thermal conductivity was measured between 198 and $214 \mathrm{~W} \mathrm{~m}^{-1} \mathrm{~K}^{-1}$. Preparation of the samples before irradiation was already described elsewhere [18]. Briefly, they were polished with diamond suspensions down to $1 \mu \mathrm{m}$, and then subsequently irradiated with different swift heavy ions (SHI). This kind of irradiation aims to simulate the interactions of fission products without the drawback of neutrons activating the specimens. Thus, the specimens can be manipulated just after irradiations without any particular precautions.

SHI were provided by GANIL facilities (Caen, France). In order to know the effect of electronic stopping power, samples were irradiated with different ion-energy couples. Table 1 shows the effect of three ion irradiations in AlN, to wit the average projected range (Rp), both the electronic (Se) and the nuclear (Sn) stopping powers. All these data were obtained with SRIM-2008 code [19]. In addition, this table contains the experimentally reached fluences and the irradiation temperatures.

Table 1: Summary of irradiation conditions; RT stands for room temperature.

\begin{tabular}{llllll}
\hline Ion irradiation & $\mathrm{Rp}(\mu \mathrm{m})$ & $\mathrm{Se}\left(\mathrm{keV} \mathrm{nm}^{-1}\right)$ & $\mathrm{Sn}\left(\mathrm{keV} \mathrm{nm}^{-1}\right)$ & Fluences $\left(\mathrm{cm}^{-2}\right)$ & Temperatures \\
\hline $74 \mathrm{MeV} \mathrm{Kr}$ & 9.7 & 13.1 & 0.054 & $10^{12}, 10^{13}, 10^{14}, 10^{15}$ & RT \& 773 K \\
$92 \mathrm{MeV} \mathrm{Xe}$ & 9.4 & 17.7 & 0.132 & $10^{12}, 10^{13}, 10^{14}, 10^{15}$ & RT \\
$930 \mathrm{MeV} \mathrm{Xe}$ & 46.2 & 21.8 & 0.018 & $10^{11}, 10^{12}, 10^{13}, 4.5 \times 10^{13}$ & RT \& 773 K \\
\hline
\end{tabular}


Nuclear Instruments and Methods in Physics Research Section B: Beam Interactions with Materials and Atoms, 2010, 269(2), 100-104, doi:10.1016/j.nimb.2010.10.025

The fluences reached for $930 \mathrm{MeV}$ Xe irradiations are lower than those reached with the two other irradiations. This is due to the highest energy, which may heat the samples during irradiation. Thus, in order not to heat the samples, the flux used for this irradiation was lower than for the two others. The required duration for equivalent fluences were hence much higher.

\subsection{Thermally stimulated luminescence measurements}

Principle of thermally stimulated luminescence (TSL) may be found elsewhere [20,21]. For TSL measurements, specimens were excited at room temperature (RT) during five minutes by a deuterium UV-lamp (50 W) covering the 200-400 nm spectral range.

Two minutes after excitation, TSL readout was achieved by linear heating of the excited sample from RT to $673 \mathrm{~K}$ at a rate of $1 \mathrm{~K} \mathrm{~s}^{-1}$. TSL intensity was recorded by means of a photomultiplier (Philips $2018 \mathrm{~B}$ ) covering the 200-600 nm range. For spectral analyzis of TSL emission, spectra were caught by an optical multi-channel analyzer (Princeton Instruments) covering the 300-800 nm range.

\subsection{Optical absorption measurements}

Optical absorption spectrophotometry (OAS) was performed at room temperature using a Varian Carry 500 spectrophotometer equipped with a diffuse reflection sphere. The spectra were recorded on the 250-800 nm wavelength range with a scan rate of $600 \mathrm{~nm} \mathrm{~min}^{-1}$. The absorption reference was made of polytetrafluoroethylene (PTFE). For all the samples, optical absorption was measured before and after ion irradiation in the same experimental conditions. The absorption bands affected by irradiation have been characterized by the difference curve, which is obtained by subtracting the absorption spectrum of the virgin sample from the spectrum of the same sample after ion irradiation.

\section{Results}

\subsection{Thermally Stimulated Luminescence}

Typical evolution of TSL glow curves as a function of fluence is shown in Figure 1. The TSL signal of the AlN sample before irradiation consists of one broad and structureless glow curve peaking at approximately $400 \mathrm{~K}$. This broad peak is due to the presence of oxygen in the nitrogen sublattice. More precisely, it attests the presence of trapping centers (TC), certainly oxygen in substitution of nitrogen $\mathrm{O}_{\mathrm{N}}$ and/or bivalent $2 \mathrm{O}_{\mathrm{N}}$ centers $[20,22,23]$. Whatever the ion-energy couple or the irradiation temperature are, the TSL intensity decreases with increasing fluence. Moreover, neither shift of the main peak, nor presence of new TSL peaks induced by irradiation were observed. 
Nuclear Instruments and Methods in Physics Research Section B: Beam Interactions with Materials and Atoms, 2010, 269(2), 100-104, doi:10.1016/j.nimb.2010.10.025

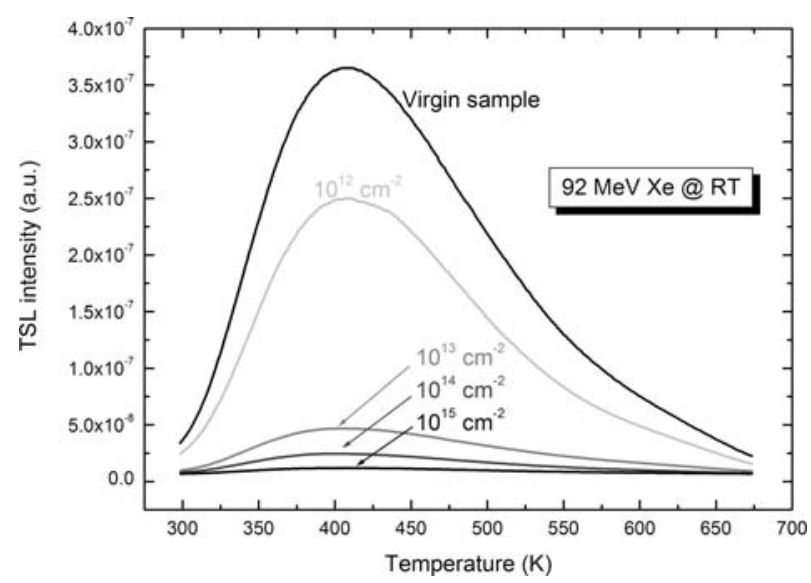

Figure 1: TSL glow curves of polycrystalline AIN sample as a function of $92 \mathrm{MeV} \mathrm{Xe}$ ion fluence.

In order to compare the TSL signal for each irradiation, we calculated the area under each glow curve; Figure 2 shows the variation of TSL area as a function of fluence for each irradiation. In this Figure, we can note three different trends. First, for $74 \mathrm{MeV} \mathrm{Kr}$ and $92 \mathrm{MeV}$ Xe irradiations at RT, TSL area quickly decreases up to $10^{13} \mathrm{~cm}^{-2}$ then tends to stabilize. Second, for irradiation at $773 \mathrm{~K}$ with $74 \mathrm{MeV} \mathrm{Kr}$ we can note a slight decrease up to $10^{13} \mathrm{~cm}^{-2}$ followed by a sharp decline occuring between $10^{13}$ and $10^{14} \mathrm{~cm}^{-2}$, then finally a stabilization of the signal. Third, whatever the temperature of $930 \mathrm{MeV}$ Xe irradiation is, TSL area decreases more swiftly than for other irradiations up to stabilization. These trends suggest that the degradation process revealed by TSL is the same for different irradiations but of similar energies.

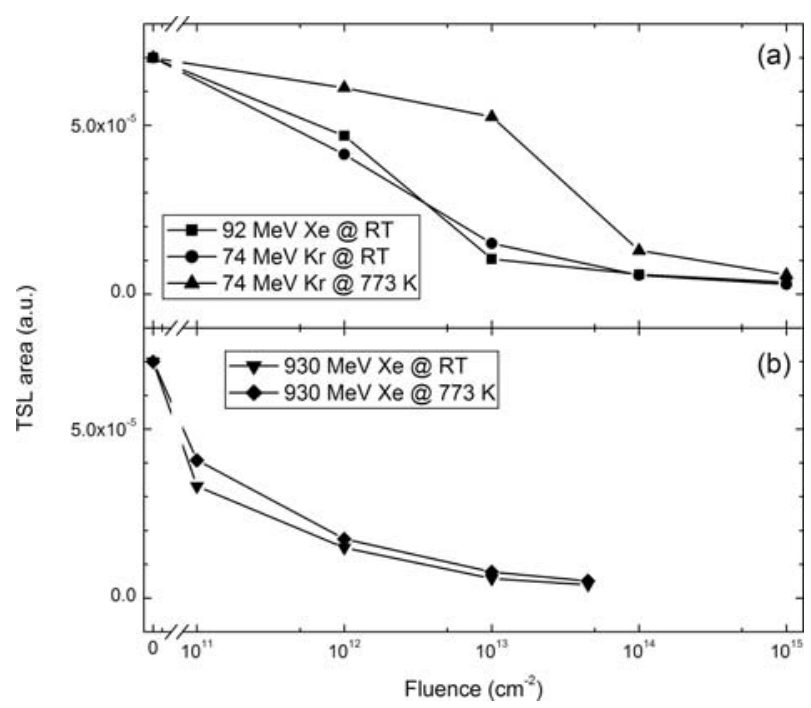

Figure 2: TSL area under glow curve as a function of ion fluence for (a) low energy irradiations, and (b) high energy irradiations; lines are only to guide the eye. 
Nuclear Instruments and Methods in Physics Research Section B: Beam Interactions with Materials and Atoms, 2010, 269(2), 100-104, doi:10.1016/j.nimb.2010.10.025

Figure 3 shows the typical evolution of TSL emission spectra of the main peak ( $400 \mathrm{~K}$ ) as a function of fluence; position of the bands was determined by Gaussian decomposition (not shown here). The spectrum of the virgin sample shows the main recombination centers (RC) in AlN already identified by Benabdesselam et al. [21]. First, the main broad band centered at around $3.2 \mathrm{eV}$ is the convolution of the emission of probably three $\mathrm{RC}$, which are more easily noticeable for the highest fluences (see inset): the emissions at $3.17 \pm 0.01 \mathrm{eV}$ and $2.67 \pm 0.17 \mathrm{eV}$ have been respectively attributed to complex centers $\mathrm{V}_{\mathrm{Al}}-\mathrm{O}_{\mathrm{N}}-3 \mathrm{~N}$ and $\mathrm{V}_{\mathrm{Al}}-2 \mathrm{O}_{\mathrm{N}}-2 \mathrm{~N}$ while the one at $3.60 \pm 0.04 \mathrm{eV}$ may be associated to transitions from $\mathrm{V}_{\mathrm{Al}}$ to $\mathrm{O}_{\mathrm{N}}$ [22]. Concerning the low bands appearing at lower energies, they might be linked to some impurities: the emission at $2.04 \pm 0.05 \mathrm{eV}$ is attributed to the presence of $\mathrm{Mn}^{4+}$ in substitution of $\mathrm{Al}^{3+}$ $\left(\mathrm{Mn}_{\mathrm{Al}}\right)$ [21] whereas that centered at $1.79 \pm 0.03 \mathrm{eV}$ has been reported by Martin et al. as being due to the presence of $\mathrm{Cr}^{3+}$ in substitution of $\mathrm{Al}^{3+}\left(\mathrm{Cr}_{\mathrm{Al}}\right)$ [24]. Inductively coupled plasma (ICP) analyzis confirmed the presence of both impurities in our samples, at concentrations of $1.9 \pm 0.1$ and $2.0 \pm 0.1 \mathrm{ppm}$ respectively.

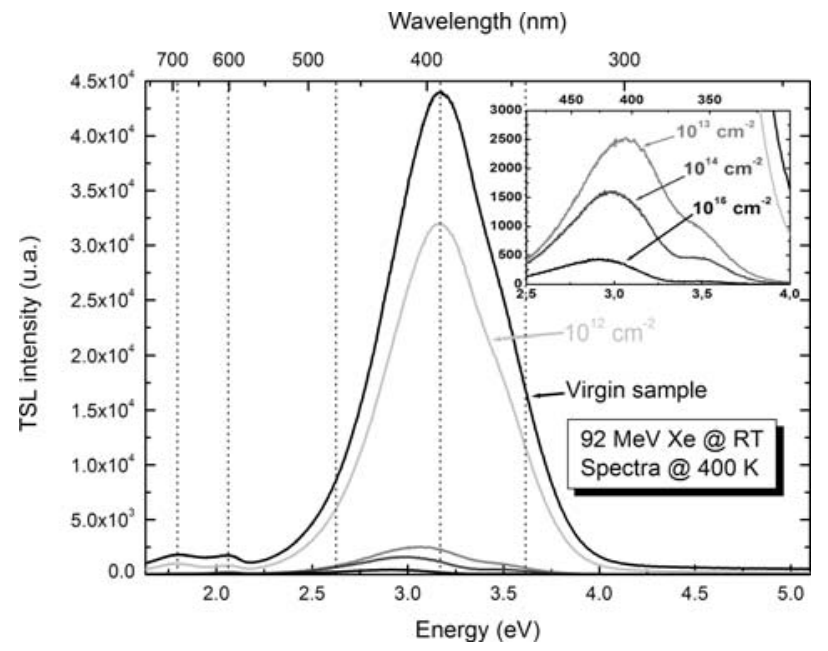

Figure 3: Spectral distribution of the main TSL peak (400 K) as a function of $92 \mathrm{MeV}$ Xe ion fluence in polycrystalline AlN samples; the inset is a zoom of the main emission band for the highest fluences.

After irradiation, it is interesting to remark that no new RC is created: as shown for the glow curves, the intensity of the spectra decreases with the fluence, whatever the irradiation is.

\subsection{Optical absorption spectrophotometry}

Figure 4a shows the optical absorption spectrum of AlN before irradiation. It presents several absorption bands in the 250-800 nm range. In this Figure, one can see the spectrum of the sample irradiated at RT with $92 \mathrm{MeV}$ Xe to $10^{15} \mathrm{~cm}^{-2}$; as explained in section 2.3., the induced absorption was obtained by subtracting the absorption spectrum of a virgin sample from that of the same sample after ion irradiation. 
Nuclear Instruments and Methods in Physics Research Section B: Beam Interactions with Materials and Atoms, 2010, 269(2), 100-104, doi:10.1016/j.nimb.2010.10.025
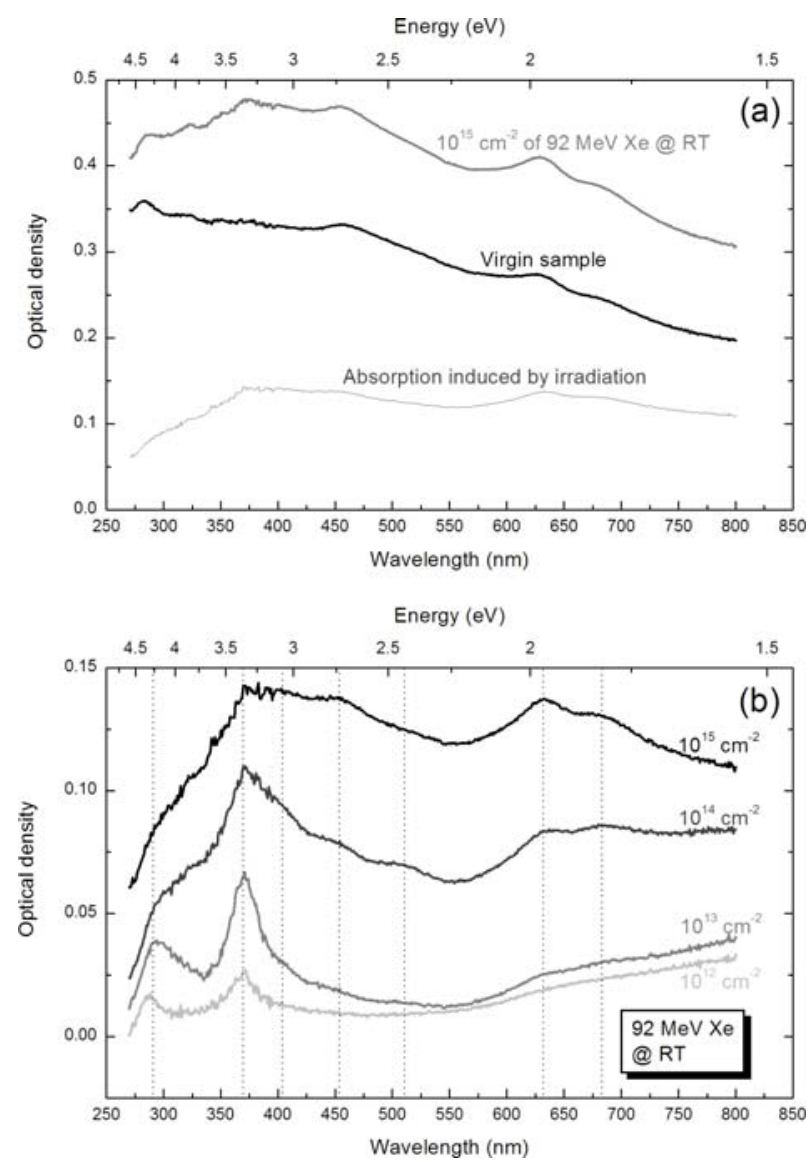

Figure 4: Optical absorption of polycristalline AlN in the 250-800 nm wavelength range: (a) comparison between the virgin sample and the same sample irradiated at room temperature with $92 \mathrm{MeV} \mathrm{Xe} \mathrm{to} 10^{15} \mathrm{~cm}^{-2}$, and (b) optical absorption bands induced by $92 \mathrm{MeV}$ Xe irradiation.

Through the $92 \mathrm{MeV}$ Xe irradiations, Figure $4 \mathrm{~b}$ shows the typical evolution of the absorption induced by irradiation as a function of fluence. In this Figure, one can see an increase of the absorption with the fluence all over the studied range. After irradiation, the optical density of 7 bands increases more particularly; the energy of these bands (Table 2) was determined after Gaussian decomposition of the obtained spectra (not shown here). Each of these 7 bands was ever on the absorption spectrum of the virgin sample: irradiations do not induce any new absorbing defect in the 250-800 nm range. 
Nuclear Instruments and Methods in Physics Research Section B: Beam Interactions with Materials and Atoms, 2010, 269(2), 100-104, doi:10.1016/j.nimb.2010.10.025

Table 2: Identification of absorption bands affected by $92 \mathrm{MeV}$ Xe irradiation in polycristalline AlN sample; F centers are defects based on anionic vacancies.

\begin{tabular}{llll}
\hline$\lambda(\mathrm{nm})$ & $\mathrm{E}(\mathrm{eV})$ & Related defect & References \\
\hline $678 \pm 7$ & $1.83 \pm 0.02$ & $\mathrm{Cr}^{3+}$ (zero-phonon) & {$[25-29]$} \\
$630 \pm 6$ & $1.97 \pm 0.02$ & $\mathrm{Fe}_{\mathrm{Al}}$ & {$[30]$} \\
$511 \pm 6$ & $2.43 \pm 0.03$ & $?$ & \\
$455 \pm 9$ & $2.73 \pm 0.05$ & $\mathrm{~V}_{\mathrm{N}}$ or $\mathrm{Al}_{\mathrm{i}}$ or F$_{2}{ }^{2+}$ & {$[31-36]$} \\
$406 \pm 8$ & $3.06 \pm 0.06$ & $\mathrm{~V}_{\mathrm{Al}}$ or $\mathrm{Cr}_{\mathrm{Al}}$ & {$[37,38]$} \\
$370 \pm 6$ & $3.35 \pm 0.05$ & $\mathrm{~F}_{2}^{+}$ & {$[39]$} \\
$290 \pm 8$ & $4.28 \pm 0.12$ & $\mathrm{O}$ related center $\left(\mathrm{F}_{2}\right.$ ?) or $\mathrm{Al}_{\mathrm{i}}$ & {$[36,40-42]$} \\
\hline
\end{tabular}

In the literature, few information are available concerning the identification of absorbing defects in AlN. The data presented in Table 2 has been performed using those from other materials, in particular from alumina. Indeed, according to the high chemical affinity of oxygen towards aluminum, it is likely that a thin layer of alumina is present on the surface of AlN samples. Finally, as for the impurities of both manganese and chromium observed in the TSL emission spectra, the presence of iron in AIN samples (Table 2) was clearly identified by ICP, at a ratio of $330 \pm 20 \mathrm{ppm}$.

\section{Discussion}

The estimation of the concentration of each absorbing defect (AD) is complicated. However, for each irradiation parameter, we observed that when an absorption band increases, all the other bands do likewise, even if not with the same rate (Figure 4b); this observation was also right for decrease of the optical density of the irradiated sample compared with that of the virgin one. That is why, in order to understand the effects of SHI in AlN material, we decided to follow the variation of the overall absorption of each sample as a function of irradiation parameters by calculating, for each performed irradiation, the average of the optical density induced by irradiation; this global absorption was called average optical absorption induced by irradiation (Figure 5). 
Nuclear Instruments and Methods in Physics Research Section B: Beam Interactions with Materials and Atoms, 2010, 269(2), 100-104, doi:10.1016/j.nimb.2010.10.025

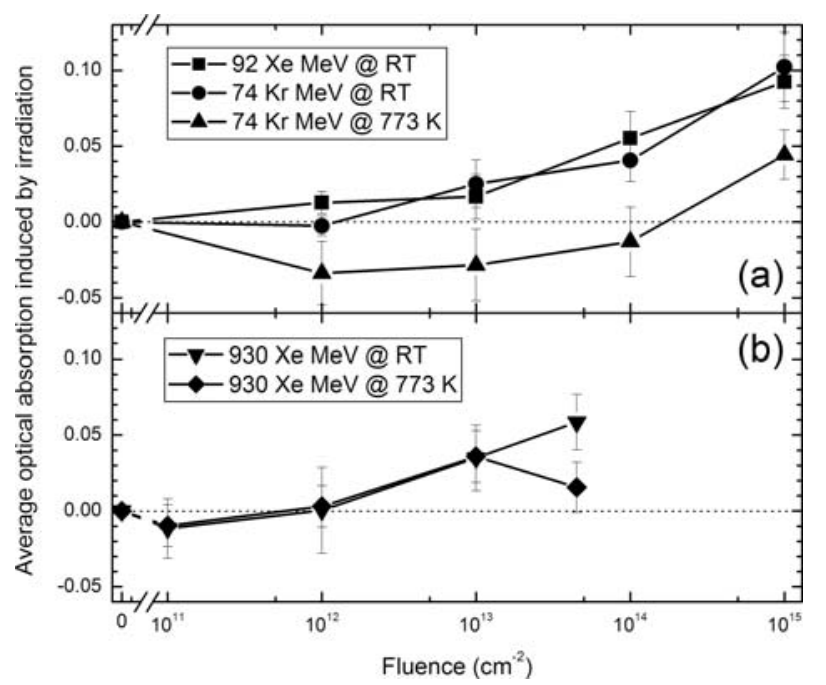

Figure 5: Average optical absorption induced by (a) low energy irradiations, and (b) high energy irradiations within the 250-800 nm wavelength range; lines are only to guide the eye.

Thus, whatever the irradiation carried out at RT is, the induced absorption remains constant and almost null up to $10^{12} \mathrm{~cm}^{-2}$, and then increases. For irradiations performed at $773 \mathrm{~K}$ with $930 \mathrm{MeV} \mathrm{Xe}$ ions, the variation is similar to that at RT except for highest fluence of $4.5 \times 10^{13} \mathrm{~cm}^{-2}$ for which the induced absorption decreases slightly at $773 \mathrm{~K}$ while it increases for RT. This behavior could be explained by an annealing of the defects created by irradiation from a critical fluence $\phi_{\mathrm{c}}$ ranging between $10^{13}$ and $4.5 \times 10^{13} \mathrm{~cm}^{-2}$ at $773 \mathrm{~K}$. Thus, above $\phi_{\mathrm{c}}$ the defects would be annealed, inducing a decrease of the overall concentration of defects. Finally, for the $74 \mathrm{MeV} \mathrm{Kr}$ irradiation at $773 \mathrm{~K}$, we observe a sharp drop in absorption compared to the virgin sample. This drop is followed by the same increase with the fluence as obtained for irradiation at RT: the average induced absorption hence reachs a comparable value to that before irradiation for $10^{14} \mathrm{~cm}^{-2}$ fluence, and becomes higher for $10^{15} \mathrm{~cm}^{-2}$. Thus, if the electronic stopping power Se decreases (13.1 $\mathrm{keV} \mathrm{nm}^{-1}$ for $74 \mathrm{MeV} \mathrm{Kr}$ and $21.8 \mathrm{keV} \mathrm{nm}^{-1}$ for $930 \mathrm{MeV}$ Xe, see Table 1), the critical fluence of annealing $\phi_{\mathrm{c}}$ decreases, being lower than $10^{12} \mathrm{~cm}^{-2}$ for irradiation at $773 \mathrm{~K}$ with $74 \mathrm{MeV} \mathrm{Kr}$. Moreover, the evolution of this average induced absorption reflects a balance between annealing by irradiation temperature and creation of defects by irradiation itself, which inclines toward the creation only for high fluences.

Thanks to OAS, we know that irradiations create defects that absorb the UV-visible radiations, and therefore some of the TSL emissions mainly located in this range. To better understand the irradiation effects due to SHI, we now compare the results obtained by both techniques.

First, by considering the annealing at $773 \mathrm{~K}$ of the absorbing defects induced by $74 \mathrm{MeV} \mathrm{Kr}$ ion irradiation (Figure 5a), one would expect an increase of the TSL signal for low $74 \mathrm{MeV} \mathrm{Kr}$ fluences, above the signal of the virgin sample. 
Nuclear Instruments and Methods in Physics Research Section B: Beam Interactions with Materials and Atoms, 2010, 269(2), 100-104, doi:10.1016/j.nimb.2010.10.025

However, according to Figure 2a, the TSL signal also decreases for this irradiation. Therefore, this ion-energy couple (74 MeV Kr) seems to induce the decrease of TSL center concentration. Moreover, regarding the fact that there is no difference between the TSL signals related to $930 \mathrm{MeV}$ Xe irradiations performed at RT and $773 \mathrm{~K}$, we can consider that an increase of the irradiation temperature does not induce any increase of TSL center concentration, but only the annealing of $\mathrm{AD}$. Therefore, the differences between the TSL curves of $74 \mathrm{MeV} \mathrm{Kr}$ ion irradiations would be only due to both the creation of $\mathrm{AD}$ at RT and their annealing at $773 \mathrm{~K}$.

Second, for the same fluences and for irradiations performed at RT, TSL signal is nearly the same for both $74 \mathrm{MeV} \mathrm{Kr}$ and $92 \mathrm{MeV}$ Xe irradiations, and then decreases in the case $930 \mathrm{MeV}$ Xe irradiation. As for these irradiations the AD concentration is the same whatever the electronic stopping power is, this latter has not any effect on TSL center concentration up to a threshold $\mathrm{Se}_{\mathrm{th}}$ above which this concentration strongly decreases; according to data reported in Table 1, this threshold would be between 17.7 and $21.8 \mathrm{keV} \mathrm{nm}^{-1}$.

Eventually, when the fluence increases at RT, we noted that both the AD concentration increases in the same way whatever the Se is, and the TSL signal decreases as a function of Se. Therefore, the decrease of TSL signal as a function of the fluence cannot directly be attributed to the creation of AD. So we can conclude that when the fluence increases, the concentration of TSL centers decreases.

Thus, by comparing the TSL and OAS signals we now understand the effect of each irradiation parameter on the concentrations of both TSL centers and AD. But how to justify the fact that TSL center concentration decreases when either the electronic stopping power or the fluence increases? The first hypothesis is that, following the thermal spike model [43,44], electronic stopping power provides heat in the material through electron-phonon interactions. This heat could induce some annealing effect as ever remarked by Benyagoub et al. in silicon carbide [45]. Thus, the TSL center would be annealed, explaining the decrease of the TSL signal when increasing the fluence. Nevertheless, TSL centers observed in our specimens being due to the substitution of both $\mathrm{Al}$ and $\mathrm{N}$ atoms by impurities (oxygen, chromium, manganese, ...), their annealing appears to be difficult. Therefore, we rather think that electronic stopping power induces some modifications of these TSL centers. For instance, $\mathrm{Mn}^{4+}$ which is in substitution of $\mathrm{Al}^{3+}$ may be ejected from its site $\mathrm{Mn}_{\mathrm{Al}}$ and becomes an intersticial $\mathrm{Mn}_{\mathrm{i}}$, or the complex centers $\mathrm{V}_{\mathrm{Al}}-\mathrm{O}_{\mathrm{N}}-3 \mathrm{~N}$ and $\mathrm{V}_{\mathrm{Al}}-2 \mathrm{O}_{\mathrm{N}}-2 \mathrm{~N}$ may be dissociated by Se; these modifications may also be met with trapping centers such as oxygen in substitution of nitrogen. This hypothesis would explain the decrease of the concentration of TSL centers all the while creating other (absorbing) defects in the material. Whatever the hypothesis is, further characterisations would be necessary; for example, photoluminescence measurements would allow us to know the variation of the recombination center concentration as function of the irradiation parameters. 
Nuclear Instruments and Methods in Physics Research Section B: Beam Interactions with Materials and Atoms, 2010, 269(2), 100-104, doi:10.1016/j.nimb.2010.10.025

\section{Conclusion}

In this study, we first identified both trapping and recombination centers by thermally stimulated luminescence, but not all the absorbing defects are affected by SHI irradiation. A major result is that whatever the analytical technique is, no new defect was detected after these irradiations.

Second, thanks to the fact that TSL and OAS complement each other, we discriminated the effect of fluence, electronic stopping power, and temperature on the overall concentration of both TSL centers and AD. Thus, the higher the fluence, the lower the TSL center concentration, and the higher the AD concentration. Moreover, we defined an electronic stopping power threshold $\mathrm{Se}_{\mathrm{th}}$, which ranges between 17.7 and $21.8 \mathrm{keV} \mathrm{nm}^{-1}$, above which the TSL center concentration strongly decreases. On the contrary, when $\mathrm{Se}<\mathrm{Se}_{\mathrm{th}}$, the electronic stopping power has no effect on both TSL centers and AD concentrations. Concerning the temperature, we concluded that this parameter has no effect on TSL center concentration, whereas it induces the decrease of the $\mathrm{AD}$ concentration if the fluence is higher than a critical fluence $\phi_{c}$ which depends on ion-energy couple. This result is quite encouraging for application of aluminum nitride as a component of fuel for the GFR, which should operate at temperatures well above $773 \mathrm{~K}$.

Eventually, we tryed to know how the TSL signal decreases as a function of both electronic stopping power and fluence, and our hypothesis is that irradiations induce a change of the TSL centers, creating non-luminescent defects.

\section{Acknowledgment}

Authors would like to gratefully thank Isabelle Monnet (GANIL) for her great help during the irradiation of the samples. They also would like to thank Yves Jorand (INSA, Lyon, France) for providing the virgin materials. This study was partly funded by the French research group MATINEX.

\section{References}

[1] R. Couturier, D. Ducret, P. Merle, J. P. Disson, P. Joubert, Elaboration and characterization of a metal matrix composite: Al/AIN, J. Eur. Ceram. Soc. 17 (1997) 1861-1866.

[2] F. Roulet, P. Tristant, J. Desmaison, R. Rezakhanlou, M. Ferrato, Corrosion behaviour of aluminium nitride in liquid aluminium: Influence of the microstructure, J. Eur. Ceram. Soc. 17 (1997) 1877-1883.

[3] J. Jarrige, J.P. Lecompte, J. Mullot, G. Müller, Effect of oxygen on the thermal conductivity of aluminium nitride ceramics, J. Eur. Ceram. Soc. 17 (1997) 1891-1895.

[4] A.V. Virkar, T.B. Jackson, R.A. Cutler, Thermodynamic and Kinetic Effects of Oxygen Removal on the Thermal Conductivity of Aluminum Nitride, J. Am. Ceram. Soc. 72 (1989) 2031-2042. 
Nuclear Instruments and Methods in Physics Research Section B: Beam Interactions with Materials and Atoms, 2010, 269(2), 100-104, doi:10.1016/j.nimb.2010.10.025

[5] G.A. Slack, S.F. Bartram, Thermal expansion of some diamondlike crystals, J. Appl. Phys. 46 (1975) 89-98.

[6] L.H. Rover, G.R. Hopkins, Nucl. Technol. 29 (1976) 274.

[7] T. Yano, K. Inokuchi, M. Shikama, J. Ukai, S. Onose, T. Maruyama, Neutron irradiation effects on isotope tailored aluminum nitride ceramics by a fast reactor up to 2 × 1026 n/m2, J. Nucl. Mater. 329-333 (2004) 1471-1475.

[8] Abdeslem Hafidi, Contribution à l'étude des propriétés thermiques de céramiques à base de nitrure d'aluminium, Thèse de doctorat, spécialité Sciences des Matériaux. Université de Limoges (1992).

[9] T. Yano, T. Iseki, A HREM study of neutron-irradiation-induced dislocations in aluminum nitride, Philos. Mag. Lett. 62 (1990) 83-87.

[10] T. Yano, H. Miyazaki, T. Iseki, Effect of isochronal annealing on thermal diffusivity of neutron-irradiated AlN, J. Nucl. Mater. 230 (1996) 74-77.

[11] T. Yano, T. Iseki, High-resolution electron microscopy of neutron-irradiation-induced dislocations in SiC, Philos. Mag. A 62 (1990) 421-430.

[12] T. Yano, M. Tezuka, H. Miyazaki, T. Iseki, Macroscopic length, lattice-parameter and microstructural changes in neutron-irradiated aluminum nitride due to annealing, J. Nucl. Mater. 191 (1992) 635-639.

[13] C.S. Kim, T. Iseki, T. Yano, M. Tezuka, Mechanical-properties of neutron-irradiated AlN, J. At. Energy Soc. Jpn. 34 (1992) 335-341.

[14] T. Yano, K. Ichikawa, M. Akiyoshi, Y. Tachi, Neutron irradiation damage in aluminum oxide and nitride ceramics up to a fluence of 4.2 x 10(26) n/m(2), J. Nucl. Mater. 283 (2000) 947-951.

[15] T. Yano, T. Iseki, Swelling and microstructure of AlN irradiated in a fast-reactor, J. Nucl. Mater. 203 (1993) 249-254.

[16] T. Yano, T. Iseki, Thermal and mechanical-properties of neutron-irradiated aluminum nitride, J. Nucl. Mater. 179 (1991) 387-390.

[17] M. Akiyoshi, I. Takagi, T. Yano, N. Akasaka, Y. Tachi, Thermal conductivity of ceramics during irradiation, Fusion Eng. Des. 81 (2006) 321-325.

[18] J.C. Nappé, Ph. Grosseau, F. Audubert, B. Guilhot, M. Beauvy, M. Benabdesselam, I. Monnet, Damages induced by heavy ions in titanium silicon carbide: Effects of nuclear and electronic interactions at room temperature, J. Nucl. Mater. 385 (2009) 304-307.

[19] J.F. Ziegler, <http://www.srim.org/>.

[20] F. Porte, J.P. Lecompte, J. Jarrige, A. Collange, P. Grosseau, B. Guilhot, Thermoluminescence of aluminium nitride: Influence of the thermal treatment, J. Eur. Ceram. Soc. 17 (1997) 1797-1802. 
Nuclear Instruments and Methods in Physics Research Section B: Beam Interactions with Materials and Atoms, 2010, 269(2), 100-104, doi:10.1016/j.nimb.2010.10.025

[21] M. Benabdesselam, P. Iacconi, D. Lapraz, Ph. Grosseau, B. Guilhot, Thermoluminescence of AlN. Influence of synthesis processes, J. Phys. Chem. 99 (1995) 10319-10323.

[22] J. Rosa, I. Tale, Mechanism of thermoluminescence in Al:O, Czech. J. Phys. 29 (1979) 810-824.

[23] L. Trinkler, P. Christensen, N.A. Larsen, B. Berzina, Thermoluminescence properties of AlN ceramics, Radiat. Meas. 29 (1998) 341-348.

[24] A.L. Martin, C.M. Spalding, V.I. Dimitrova, P.G. Van Patten, M.L. Caldwell, M.E. Kordesch, H.H. Richardson, Visible emission from amorphous AlN thin-film phosphors with $\mathrm{Cu}$, Mn, or Cr, J. Vac. Sci. Technol. A: Vac Surf. Films 19 (2001) 1894-1897.

[25] M.A.F.M. da Silva, R.B. Barthem, L.P. Sosman, Investigation of luminescence and optical absorption of K2LiAlF6:Cr3+ single crystals, J. Solid State Chem. 179 (2006) 3718-3723.

[26] I. Sokólska, S. Kück, Optical characterization of Cr3+ doped LiTaO3 crystals relevant for laser application, Spectrochim. Acta Part A: Mol. Biomol. Spectrosc. 54 (1998) 1695-1700.

[27] G.M. Salley, S.A. Basun, A.A. Kaplyanskii, R.S. Meltzer, K. Polgar, U. Happek, Chromium centers in stoichiometric LiNbO3, J. Lumin. 87-89 (2000) 1133-1135.

[28] M.G. Brik, Crystal field analysis, electron-phonon coupling and spectral band shape Modeling in MgO:Cr3+, Z. Naturforsch. A: J. Phys. Sci. 60 (2005) 437-443.

[29] M.G. Brik, V.A. Lebedev, E.V. Stroganova, Spectroscopic and crystal field studies of (Ce,Gd)Sc3 (BO3)4:Cr3+ crystals, J. Phys. Chem. Solids 68 (2007) 1796-1804.

[30] A.R. Moon, M.R. Phillips, Defect clustering and color in Fe,Ti: [alpha]-Al2O3, J. Am. Ceram. Soc. 77 (1994) 356-367.

[31] K. Kawabe, R.H. Tredgold, Y. Inuishi, Electrical and optical properties of AlN - a thermostable semiconductor, Electr. Eng. Jpn. 87 (1967) 62-70.

[32] G.A. Cox, D.O. Cummins, K. Kawabe, R.H. Tredgold, On the preparation, optical properties and electrical behaviour of aluminium nitride, J. Phys. Chem. Solids 28 (1967) 543-548.

[33] T.L. Tansley, R.J. Egan, Point-defect energies in the nitrides of aluminum, gallium, and indium, Phys. Rev. B 45 (1992) 10942.

[34] T. Mattila, R.M. Nieminen, Ab initio study of oxygen point defects in GaAs, GaN, and AlN, Phys. Rev. B 54 (1996) 16676-16682.

[35] M. Bickermann, B.M. Epelbaum, A. Winnacker, Characterization of bulk AlN with low oxygen content, J. Cryst. Growth 269 (2004) 432-442. 
Nuclear Instruments and Methods in Physics Research Section B: Beam Interactions with Materials and Atoms, 2010, 269(2), 100-104, doi:10.1016/j.nimb.2010.10.025

[36] B.D. Evans, G.J. Pogatshnik, Y. Chen, Optical properties of lattice defects in [alpha]-Al2O3, Nucl. Instrum. Methods Phys. Res. Sect. B: Beam Interact. Mater. Atoms 91 (1994) 258-262.

[37] T.J. Turner, J.H. Crawford, V centers in single crystal Al2O3, Solid State Commun. 17 (1975) 167-169.

[38] D. Lapraz, Ph. Iacconi, D. Daviller, B. Guilhot, Thermostimulated luminescence and fluorescence of [alpha]Al2O3:Cr3+ samples (Ruby): influence of the Cr3+ concentration, Phys. Status Solidi (a) 126 (1991) 521-531.

[39] M. Beauvy, C. Dalmasso, C. Thiriet-Dodane, D. Simeone, D. Gosset, Damages in ceramics for nuclear waste transmutation by irradiation with swift heavy ions, Nucl. Instrum. Methods Phys. Res. Sect. B: Beam Interact. Mater. Atoms 242 (2006) 557-561.

[40] J. Pasternak, L. Roskovcova, Optical absorption end of AlN single crystals, Phys. Status Solidi 26 (1968) 591.

[41] G.A. Slack, L.J. Schowalter, D. Morelli, J.A. Freitas, Some effects of oxygen impurities on AlN and GaN, J. Cryst. Growth 246 (2002) 287-298.

[42] M.J. Springis, J.A. Valbis, Visible luminescence of colour centres in sapphire, Phys. Status Solidi (b) 123 (1984) 335-343.

[43] M. Toulemonde, C. Dufour, E. Paumier, Transient thermal-process after a high-energy heavy-ion irradiation of amorphous metals and semiconductors, Phys. Rev. B 46 (1992) 14362-14369.

[44] M. Toulemonde, E. Paumier, C. Dufour, Thermal spike model in the electronic stopping power regime, Radiat. Eff. Defects Solids 126 (1993) 201-206.

[45] A. Benyagoub, A. Audren, L. Thome, F. Garrido, Athermal crystallization induced by electronic excitations in ion-irradiated silicon carbide, Appl. Phys. Lett. 89 (2006) 241914. 